\title{
History OF MEDicine
}

\section{The Poisonous Past: Circe, Helvetius, Touéry, and a Brief History of Emergency Decontamination}

\author{
Rosalind Ashton', Constance LeBlanc ${ }^{2}$ \\ 'Class of 2012, Faculty of Medicine, Dalhousie University \\ ${ }^{2}$ Department of Emergency Medicine, Dalhousie University
}

You can't talk of the dangers of snake poisoning and not mention snakes

C. Everett Koop

The history of toxicology is lengthy and extremely colourful; it is a field that dates back more than 10,000 years. Poisons have been known, used, and feared by individuals in every era and social class. They have also given us some of the most dramatic stories of assassination plots, crimes of passion, and mass suicides. Fascination with poison and the romantic idea of the antidote has roots in ancient mythology and continues as a theme in literature and movies. Homer's Odyssey (9th c. B.C.) was probably one of the first literary descriptions of this; Odysseus took 'moly' which was most likely Galanthus nivalis (snowdrop), a cholinesterase inhibitor, to escape the consequences of Circe's potion and free his captive men from her island. Circe's poison has been depicted in many pieces of art as an apple, most likely the thorn apple, which contains anticholingeric agents. While it is unlikely that a concoction prepared with thorn apple could turn a dozen men into swine and threaten their epic voyage, this chapter of the Odyssey illustrates the use of poison as a manipulative tool and the antidote as a saviour.

Accidental poisoning is, unfortunately, not uncommon in North America. The American Association of Poison Control Centres estimates that 2.4 million people are brought to the emergency department (ED) annually for toxic ingestions. By the 1930s, it was estimated that $50 \%$ of unintentional childhood injuries in North America were due to poisonings and this statistic has not changed over time. ${ }^{1}$ The preferred method of decontamination in the ED has had a variable history. The literature has debated whether certain methods are more effective and the optimal timing for each. In addition, the list of contraindications for each method grows annually. Common methods of decontamination have included the use of activated charcoal, gastric lavage, cathartics, whole bowel irrigation, and syrup of ipecac.

This paper provides a brief history of two agents that stem from natural and ancient roots, one of which continues to be used often and one which has fallen out of favour in the ED: activated charcoal and ipecac, respectively.

\section{Activated Charcoal}

Activated charcoal is capable of binding to diverse substances, making it an excellent antidote for poisoning. It prevents systemic absorption of toxins from the gastrointestinal tract through its adsorptive properties (adsorb means to collect in a condensed form on a surface, rather than 'absorb' which means to 'suck up'). It is obtained as a product of pyrolysis of numerous organic substances such as wood, coconut shell, and peat, which are "activated" by heating to 600 to 900 degrees Celsius, a process which creates a small particle size, increasing the surface area, and ameliorating adsorption. ${ }^{2}$ The discovery of charcoal's decontamination potential is generally attributed to the organic chemist Carl Wilhelm Scheele (1742-1786), who in 1773 described experiments consisting of introducing glowing charcoal into an inverted tube filled with gas. The charcoal adsorbed the gas, demonstrated by the rise of a drop of mercury hovering at the bottom of the tube. Soon after, liquid charcoal was tested and began to be used industrially for decolourizing sugar solutions. Purification and filtration were known properties of activated charcoal and these effects were used in a number of cultures for various purposes, even in ancient times. Hindu documents from 450 B.C. record the use of charcoal and sand filters for the purification of drinking water and recent studies of the wrecks of Phoenician trading ships suggest that 
drinking water was stored in charred wooden barrels, also for this reason. This practice was still used during the 18th century for extending the use of potable water on long sea voyages. ${ }^{5}$

Activated charcoal for medicinal purposes was described as early as 1550 B.C. in Egyptian papyruses. Egyptian priests used it to eliminate the odours arising from festering wounds and as a preventative measure for flatulence. Its ability to neutralize the unpleasant aromatic properties of ulcers and wounds is perhaps its most long-standing use. It has also been described in 1793 and well into the 19th century as a treatment for gangrenous ulcers; it was powdered and sprinkled into lesions. ${ }^{5}$

According to Holt and Holz, two of the most prolific researchers of activated charcoal properties, the first official trials looking at its effectiveness as a remedy for poison began in the 1800s. During this time several risky demonstrations were undertaken. Chemist Gabriel Bertrand (1867-1962) had studied arsenic poisoning in animals and was reputed to have given a public show of charcoal's effectiveness "by swallowing 5 grams of arsenic trioxide mixed with charcoal." In 1831, the French pharmacist Pierre Touéry, determined to impress upon a crowd at the French Academy of Medicine in Paris that activated charcoal could counteract the effects of poison, swallowed ten times the lethal dose of strychnine with 15 grams of activated charcoal and survived. The Academy was not overly impressed and, despite this dramatic display of its merits, activated charcoal continued to only be used for industrial purposes, such as removing impurities from beer and sugar.

It was not until 1963, after a seminal review article was published in the Journal of Pediatrics by Holt and Holz that activated charcoal became widely accepted in the emergency management of ingested toxins. The authors concluded that "activated charcoal is the most valuable agent in treating acute poisonings"7 and after the publication, its use became widespread. Activated charcoal continues to be an important part of the early management of selected cases of poisoning. ${ }^{7}$

\section{Syrup of Ipecac}

The only emetic that ever gained popularity in the emergency department is syrup of ipecac. Derived from the dried root of ipecacuana, ipecac was discovered in Brazil by Portuguese explorers around 1625 and brought to Europe by the Dutch physician William Piso (1611-1678) in 1649. During the early 1600s, commercial traffic between Portugal, Spain, and France and the New World kept doctors, merchants, and priests regularly crossing the Atlantic in search of new medicine, especially following the exciting discovery of the Peruvian bark Cinchona (quinine) by the Jesuits.

Used in Brazil (where it was known as Igpecaya: loosely translated from its Portuguese derivative as the 'roadside vomiting plant') for the treatment of dysentery, ipecac was made exponentially more famous in Europe through a royal connection. Claude-Adrien Helvetius, a "quack physician" living in France, prepared a secret preparation of ipecac which he called Radix Antidysenterica, ${ }^{10}$ and regularly gave it to patients complaining of stomach ailments. King Louis XIV's son, the dauphin, contracted "the flux" (dysentery) which escaped all remedies of the court physicians. Legend has it that Helvetius' potion cured the sickly dauphin and that the king authorized his court physicians to negotiate with Helvetius for the publication of this secret formula, which he eventually sold for a hefty thousand Louis d'Or to the French government. ${ }^{9}$

When the root and powder became widely available in Europe in the eighteenth century, its indications were studied more extensively. It was established that, in small doses, ipecac was a diaphoretic and expectorant, and in larger doses, it was an emetic and cathartic. This made it a very useful substance since the miasma (Greek for pollution) theory of disease still held strong. If the 'bad humours' could be expelled by purging, a person was able to restore their inner balance and recover quickly. Following this logic, ipecac became a popular supplement to traditional methods of restoring the balance of the humours, including bleeding and cupping, and Ipecac as a treatment was born.

No history of ipecac would be complete without mention of "Dover's Powder." Dr. Thomas Dover (1662-1742) was a cantankerous physician in London and Bristol who came to be known as the "quicksilver doctor" for his vocal support and use of mercury in the treatment of syphilis and other venereal disease. Besides this work, he is also famous for "Dover's Powder" (pulvis ipecachuana), which was used for over 200 years in England as a treatment for gout. The major ingredients were ipecachuana, opium, saltpetre, and cream of tartar and he would often suggest taking a dose of 60 to 80 grams at one time.

Beginning in 1966, syrup of ipecac was available in most pharmacies without a prescription and many people were encouraged to keep it on hand, particularly parents and daycare workers. It was, however, brought into question in the 1980 s by 
Niederman and Dershewitz. Their paper, "Ipecac at home - a health hazard?" suggested that ipecac actually did more harm than good. In addition, Wrenn et al. suggested that it only induced vomiting about 9 to $38 \%$ of the time. Between 1986 and 1992, the use of syrup of ipecac in EDs fell by $71 \%$ as activated charcoal replaced it as the decontamination method of choice and by 2003 , less than $1 \%$ of all toxic ingestions were treated with ipecac. Largely abandoned by the 1990s due to doubts regarding how much poison was actually purged after administration, ipecac is no longer used in EDs. ${ }^{1}$ However, one 2008 review in Pediatric Emergency Care postulates that it may have a role in the pre-hospital setting. Routine use in the home is no longer recommended and practically speaking might only be considered if the ingestion has the potential to be severely toxic and the patient is hours away from a medical centre.

Although the field of medicine seems to be sustained by a cascade of breakthroughs, in actuality the most successful treatments have been around for centuries and remain the most consistent remedies. We have learned much about the biochemical nuances of poisons and some compounds that counteract them, but we have not yet come up with sophisticated antidotes for the myriad of possible toxic ingestions. Often we have little information about the ingested toxins and rely on 'blanket' solutions to keep us covered in emergencies. As a result, activated charcoal remains an important part of the early management of selected cases of poisoning.

Humans will continually explore new compounds, many of which will be toxins. Medical science will have to work hard to keep pace with antidotes and prevent ingestions. Until then, we will continue to require decontaminants to prevent unnecessary morbidity and mortality from toxic ingestions.

\section{Acknowledgements}

We wish to thank Dr. Nancy Murphy for her comments on current recommendations.

\section{References}

1. Shannon MW, Borron SW, Burns R. Haddad and Winchester's clinical management of poisoning and drug overdose. Toronto: Saunders and Elsevier, 2007:1-5.

2. Flanagan RJ, Jones AL. Antidotes. London and New York: Taylor and Francis, 2001.

3. Watson WA, Litovitz TL, Rodgers GC. 2004 Annual report of the American association of poison control centers toxic exposure surveillance system. Am J Emerg Med 2005;23:589-666.

4. Frithson IL, Simpson WM. Recognition and management of acute medication poisoning. Am Fam Physician 2010;81(3):316-24.

5. Cooney DO. Activated charcoal: Antidotal and other medical uses.
New York and Basel: Merkel Decker Inc., 1980:1-7.

6. Lapus RM. Activated charcoal for pediatric poisonings: The universal antidote? Curr Opin Pediatr 2007;19:216-222.

7. Holt LE, Holz PH. The black bottle: A consideration of the role of charcoal in the treatment of poisoning in children. J Pediatr 1963; 63:306-214.

8. University of Kentucky Center for Applied Energy Research. "Historical production and use of carbon." Carbon Materials Research Group. <http://www.caer.uky.edu/carbon/history/ carbonhistory.shtml> (26 October 2009).

9. Wooten AC. Chronicles of Pharmacy. New York: USV Pharmaceutical Corp, 1972:114.

10. T. E. C., Jr. A brief history of Ipecac (ipecacuana). Pediatrics 1970;46(1):96.

11. Lee MR. Ipecacuanha: The South American vomiting root. J R Coll Physicians of Edinb 2008;38:355-60.

12.Duke M. Thomas Dover: Physician, pirate, and powder, as seen through looking glass of 20th-century physicians. Conn Med 1985;49(3):179-82.

13.Derschewitz RA, Neiderman LG. Ipecac at home--a health hazard? Clin Toxicol 1981;18(8):969-72.

14. Wrenn K, Rodewald L, Dockstader L. Potential misuses of ipecac. Ann Emerg Med 1993;22(9):1408-12.

15.Greene S, Harris C, Singer J. Gastrointestinal decontamination of the poisoned patient. Pediatr Emerg Care 2008;24(3): 176-190.

\section{Cape Breton Island} Great People, Great Place, Great Life

More and more people are discovering why Cape Breton Island is a great place to live, work and play. National Geographic, Fodor's Travel and Conde Naste all rank Cape Breton as one of their top destinations. Over 3,300 health care professionals \& physicians in the Cape Breton District Health Authority agree.

In planning your future career, we may be of assistance to you. Through regional, community and rural hospitals, Continuing Care, Mental Health Services, Addiction Services, Public Health Services and the Cape Breton Cancer Centre, the District serves more than 130,000 people. Cape Breton's unique beauty, diverse culture and year-round recreational opportunities make the Island a vibrant place to practice and play.

Inquiries and applications to:

Dr. M.A. Naqvi, Medical Director

Cape Breton District Health Authority

1482 George Street

Sydney, Nova Scotia B1P 1P3

Fax: (902) 567-7255

E-mail: naqvim@cbdha.nshealth.ca

Website: www.cbdha.nshealth.ca
Cape Breton District HEALTH AUTHORITY 